\title{
Analisis Burn Up pada Reaktor Pembiak Cepat Berpendingin Pb-Bi dengan Variasi Fraksi Bahan Bakar dan Bahan Pendingin
}

\author{
Nurkholilah*, Dian Fitriyani \\ Jurusan Fisika FMIPA Universitas Andalas, Padang, Indoesia \\ *nurkholilahlilah07@gmail.com
}

\begin{abstract}
ABSTRAK
Telah dilakukan simulasi pada desain Reaktor Pembiak Cepat Berpendingin Logam Cair (Pb-Bi), menggunakan kode simulasi berbasis bahasa pemograman Delphi 7.0 untuk menganalisis pembiakan bahan fisil ${ }^{239} \mathrm{Pu}$. Perhitungan diterapkan pada teras reaktor 2-D (dua dimensi) geometri r-z (silinder) dengan menempatkan bahan fertil (blanket) pada teras bagian luar. Teras reaktor dirancang beroperasi pada daya $150 \mathrm{MWt}$ dengan bahan bakar campuran uranium dan plutonium nitrida dan pendingin logam cair Pb-Bi. Simulasi dilakukan terhadap beberapa variasi fraksi bahan bakar (35\%, 40\% dan 45\%) dan bahan pendingin yang diawali dengan penyelesaian persamaan difusi untuk mendapatkan nilai faktor multiplikasi, fluks neutron dan distribusi daya. Nilai fluks yang diperoleh digunakan untuk menghitung perubahan densitas atom selama reaktor beroperasi yang diperlukan untuk menganalisis susutan bahan bakar. Hasil perhitungan menunjukkan bahwa nilai faktor multiplikasi neutron $\left(k_{e f f}\right)$ untuk semua fraksi berada dalam kondisi kritis. Untuk mencapai kondisi kritis diperlukan pengaturan enrichment, pada fraksi bahan bakar yang rendah diperlukan enrichment yang besar dan untuk fraksi bahan bakar yang tinggi diperlukan enrichment yang kecil. Pengaturan enrichment berpengaruh juga pada nilai distribusi fluks neutron, distribusi daya, densitas bahan bakar, breeding ratio dan burn up. Kinerja neutronik yang paling optimal diperoleh pada fraksi bahan bakar $45 \%$ dan pendingin 35\%. Densitas plutonium tertinggi diperoleh pada fraksi bahan bakar $45 \%$ yang merupakan hasil reaksi fisi bahan bakar setelah 1 siklus (4 tahun) operasi. Nilai pertambahan densitas isotop diketahui dari nilai Breeding Ratio (BR) yang besar dari 1 .

Kata kunci: breeding ratio, bahan fisil, burn up, reaktor pembiak cepat
\end{abstract}

\begin{abstract}
A simulation of the design of Liquid Metal Cooled Fast Breeder Reactor (Pb-Bi) has been carried out, using a simulation code based on the Delphi 7.0 programming language to analyze breeding fissile material ${ }^{239} \mathrm{Pu}$. The calculation is applied to the 2-D (two-dimensional) reactor geometry $r-z$ (cylindrical) by placing a blanket on the outer core. The core is designed to operate at $150 \mathrm{MWt}$ with a mixture of uranium and plutonium nitride and $\mathrm{Pb}$-Bi liquid metal coolant. Simulations were carried out on several variations of fuel fraction $(35 \%, 40 \%$, and $45 \%)$ and cooling material which were initiated by completion of the diffusion equation to obtain the value of multiplication factor, neutron flux and power distribution. The flux value obtained is used to calculate changes in atomic density as long as the reactor operates which is needed to analyze burn up. The calculation results show that the keff value for all fractions is in a critical condition. For critical condition needed condition enrichment, on low fuel fractions large enrichments are used and for large fuel fractions using enrichment small. The best parameter results obtained from $45 \%$ fuel fraction and $35 \%$ coolant. The highest plutonium density was obtained at $45 \%$ fuel fraction which was the result of fuel fission reaction after 1 cycle (4 years) of operation. The value of added isotope density is known sfrom the value of Breeding Ratio (BR) which is large than 1.

Keywords: Breeding Ratio, fissile material, burn up, Fast Breeding Reactor
\end{abstract}

\section{PENDAHULUAN}

Kebutuhan terhadap energi di Indonesia mengalami kenaikan sebesar 6\% per tahunnya (Yusuf, 2012). Indonesia sendiri masih dominan menggunakan sumber energi berbasis bahan fosil yang semakin menipis ketersediaannya. Sumber energi alternatif sangat diperlukan untuk memenuhi kebutuhan energi yang berkelanjutan (sustainability) di masa yang akan datang. Salah satu sumber energi alternatif yang cukup menjanjikan adalah energi nuklir.

Reaktor nuklir merupakan suatu tempat yang didesain sedemikian sehingga didalamnya dapat terjadi reaksi pembelahan inti secara berantai. Saat ini reaktor nuklir yang dikembangkan adalah reaktor generasi IV. Reaktror generasi IV adalah jenis reaktor daya yang lebih inovatif dari reaktor generasi sebelumnya. Salah satu reaktor generasi IV adalah reaktor pembiak cepat berpendingin logam cair atau LMFBR (Liquid Metal cooled Fast Breeder Reactor). 
Neutron berenergi tinggi yang diperoleh dari hasil fisi dimanfaatkan untuk mengubah bahan fertil menjadi bahan fisil sehingga pada reaktor LMFBR tidak diperlukan moderator untuk mentermalkan energi neutron. Reaktor ini dirancang dengan ukuran sedang, untuk mencapai optimalisasi reaksi. Saat reaktor cepat dapat memproduksi bahan fisil yang lebih banyak dari pada bahan fisil yang digunakan, maka reaktor ini disebut reaktor pembiak cepat (LMFBR). LMFBR merupakan salah satu jenis reaktor yang menjadi kandidat reaktor masa depan. Hal ini karena LMFBR memanfaatkan bahan bakar fertil yang melimpah di alam. U-235 yang merupakan bahan bakar fisil hanya terdapat $0,72 \%$ di alam dan sisanya merupakan bahan bakar fertil seperti U-238.

Penggunaan pendingin $\mathrm{Pb}-\mathrm{Bi}$ pada reakor cepat memberikan karakteristik neutronik paling optimal (Nurwinda, 2010). Penggunaan UN-PuN sebagai bahan bakar pada LMFBR memberikan fluks neutron dan distribusi daya paling besar serta memiliki karakteristik neutronik paling optimal dibanding dengan bahan bakar lain (Cinantya, 2014).

Penyusutan bahan bakar (burn up) terjadi setelah reaktor beroperasi dalam jangka waktu tertentu. Perhitungan burn up merupakan salah satu perhitungan standar untuk menganalisis bahan bakar reaktor. Dari perhitungan ini nilai rasio pembiakan (breeding ratio) dan level burn up selama reaktor beroperasi dapat dipantau. Rasio pembiakan merupakan perbandingan bahan fisil yang diproduksi dan yang musnah dalam satu siklus (Waltar, 2001). Adapun faktor yang mempengaruhi susutan bahan bakar diantaranya adalah pola pengisian bahan bakar dan fraksi bahan bakar yang digunakan. Fraksi bahan bakar yang digunakan dalam rancangan teras reaktor cepat berada dalam rentang 30\% - 45\% yang terdiri dari bahan fertil dan fisil.

Pada penelitian ini dilakukan analisis pengaruh fraksi bahan bakar UN-PuN terhadap nilai burn up pada reaktor cepat berpendingin timbal bismut (Pb-Bi). Fraksi bahan bakar dapat mempengaruhi banyaknya reaksi fisi yang terjadi. Reaksi fisi yang terjadi pada teras dapat mempengaruhi nilai burn up dan nilai breeding ratio.

\section{METODE}

Penelitian ini dilaksanakan pada bulan Oktober 2018 sampai Maret 2019. Program yang digunakan berupa Delphi 7.0 dengan kode komputasi FIITB.CHI. Dari simulasi ini diperoleh parameter-parameter burn up seperti fluks neutron, densitas atom, breeding ratio dan nilai burn up. Penelitian ini dilakukan di Laboratorium Fisika Nuklir Universitas Andalas.

Parameter yang digunakan dalam perancangan desain reaktor berdasarkan data dari penelitian sebelumnya (Fitriyani, 2006) dengan perubahan beberapa parameter seperti fraksi bahan bakar yang digunakan, pengayaan bahan bakar yang disesuaikan dengan bahan bakar yang digunakan serta laju aliran primer. Tabel 1 menunjukkan parameter desain reaktor cepat yang digunakan. Jenis bahan bakar yang digunakan adalah UN-PuN dengan pendingin $\mathrm{Pb}-\mathrm{Bi}$.

Tabel 1 Spesifikasi desain reaktor

\begin{tabular}{|c|c|c|}
\hline \multicolumn{2}{|l|}{ Parameter } & Spesifikasi \\
\hline \multicolumn{2}{|l|}{ Daya reaktor } & 150 MWth \\
\hline \multicolumn{2}{|l|}{ Bahan pendingin } & $\mathrm{Pb}-\mathrm{Bi}$ \\
\hline \multicolumn{2}{|l|}{ Bahan shielding } & $\mathrm{B}_{4} \mathrm{C}+$ Stainless Steel \\
\hline \multicolumn{2}{|c|}{ Bahan bakar } & UN-PuN \\
\hline \multicolumn{2}{|c|}{ Pengayaan (enrichment) bahan bakar } & $9 \%-18 \%$ \\
\hline \multicolumn{2}{|c|}{ Reactivity swing } & Maks. 0,002 \\
\hline \multirow{5}{*}{ Komponen teras : } & Diameter pin bahan bakar & $1,0 \mathrm{~cm}$ \\
\hline & Tebal cladding & $0,05 \mathrm{~cm}$ \\
\hline & Ukuran teras $\mathrm{R}, \mathrm{Z}$ & $244 \mathrm{~cm}, 116 \mathrm{~cm}$ \\
\hline & Temperatur masukan rata-rata & $300^{\circ} \mathrm{C}$ \\
\hline & Temperatur keluaran rata-rata & $500^{\circ} \mathrm{C}$ \\
\hline \multirow[t]{3}{*}{ Fraksi volume : } & Bahan bakar & Divariasikan \\
\hline & Struktur & $20 \%$ \\
\hline & Pendingin & Divariasikan \\
\hline
\end{tabular}

Perhitungan dan desain teras reaktor pada penelitian ini dilakukan secara simulasi komputasi yang diawali dengan penentuan faktor multiplikasi neutron, distribusi fluks neutron 
dan distribusi daya yang didapatkan dari penyelesaian persamaan difusi multigrup secara numerik. Persamaan multigrup dapat dilihat pada Persamaan 1.

$$
\frac{1}{V_{g}} \frac{\partial \phi_{g}}{\partial t}=\bar{\nabla} \cdot D_{g} \bar{\nabla} \phi_{g}+\Sigma_{t g} \phi_{g}(\vec{r}, t)=\sum_{g^{\prime}=1}^{G} \Sigma_{s g^{\prime}} \phi_{g^{\prime}}+\chi_{g} \sum_{g^{\prime}}^{G} v_{g^{\prime}} \Sigma_{f g^{\prime}} \phi_{g^{\prime}}+S_{g}^{e x t}
$$

dengan $D$ adalah tetapan difusi, $\phi$ adalah fluks neutron, $S_{g}{ }^{\text {ext }}$ adalah sumber neutron dari luar ke dalam, $\Sigma_{\mathrm{sg}}$ adalah penampang lintang makroskopik sumber, $\Sigma_{\mathrm{fg}}$ adalah penampang lintang makroskopik fisi.

Nilai fluks neutron hasil penyelesaian Persamaan 1 digunakan untuk analisis penyusutan bahan bakar (analisis burn up). Selama reaktor beroperasi akan dilakukan pengamatan terhadap nilai faktor multiplikasi (keff), densitas nuklida, nilai burn up dan nilai rasio pembiakan bahan fisil (breeding ratio). Persamaan yang dipakai dalam perhitungan burn up dapat dilihat pada Persamaan 2.

$$
B(\text { atom } \%)=100 \frac{\sum_{m} N_{m} \sigma_{f m} \phi_{t}}{\sum_{m} N_{m, 0}}
$$

dimana $B\left(\right.$ atom\%) adalah nilai burn up dalam $\%$ atom, $N_{m}$ adalah nilai densitas atom ke $m, \sigma_{f m}$ adalah penampang lintang mikroskopik fisi atom ke $m, \phi_{t}$ adalah distribusi fluks total dan $N_{m, 0}$ adalah densitas awal atom ke $m$. Untuk menentukan nilai breeding ratio dapat menggunakan persamaan 3 .

$$
B R=\frac{F P}{F D}
$$

dengan BR adalah nilai breeding ratio, FP adalah material fisil yang dihasilkan per siklus dan FD adalah material fisil yang hilang (terpakai).

\section{HASIL DAN DISKUSI}

\subsection{Faktor multiplikasi neutron $\left(k_{e f f}\right)$}

Faktor multiplikasi neutron merupakan acuan reaktor dalam beroperasi. Nilai $k_{\text {eff }}$ yang diperoleh selama reaktor beroperasi yaitu berkisar 1,000772 sampai 1,000888, dari nilai yang diperoleh terlihat bahwa pada semua fraksi bahan bakar yang digunakan dalam simulasi ini menunjukkan reaktor berada dalam kondisi kritis dan mampu dipertahankan selama 4 tahun beroperasi. Kondisi kritis ini dapat dicapai dengan melakukan pengaturan pada fraksi enrichment bahan bakar (bobot bahan fisil) pada masing-masing bagian teras. Keadaan ini menunjukkan bahwa reaktor mampu beroperasi dengan baik. Pengaturan enrichment dilakukan pada masing-masing fraksi bahan bakar, untuk fraksi bahan bakar yang lebih besar diatur dengan enrichment yang kecil sehingga kondisi kritis tercapai. Begitu juga dengan fraksi bahan bakar yang kecil, yaitu 35\%. Nilai $k_{\text {eff }}$ selama reoaktor beroperasi dapat dilihat pada Tabel 1.

Tabel 1 Nilai Faktor Multiplikasi dalam satu siklus (4 tahun)

\begin{tabular}{ccccc}
\hline Fraksi Bahan & \multicolumn{3}{c}{$\boldsymbol{k}_{\text {eff }}$} \\
\cline { 2 - 5 } Bakar (\%) & Tahun 1 & Tahun 2 & Tahun 3 & Tahun 4 \\
\hline 35,0 & 1,000805 & 1,000792 & 1,000782 & 1,000772 \\
40,0 & 1,000849 & 1,000835 & 1,000824 & 1,000814 \\
45,0 & 1,000888 & 1,000873 & 1,000861 & 1,000850 \\
\hline
\end{tabular}

\subsection{Distribusi Fluks Neutron}

Distribusi fluks neutron yang diperoleh untuk masing-masing fraksi bahan bakar memiliki nilai yang hamper sama. Hal ini dikarenakan adanya pengaturan enrichment pada masing-masing fraksi. Pada fraksi bahan bakar yang kecil diperlukan enrichment yang besar dan pada fraksi yang besar diperlukan enrichment yang kecil. Rata-rata enrichment pada fraksi 
bahan bakar $35 \%$ adalah $16,4 \%$; fraksi $40 \%$ adalah $15,1 \%$; dan pada $45 \%$ adalah $14,1 \%$. Nilai distribusi fluks arah radial dapat dilihat pada Gambar 1.

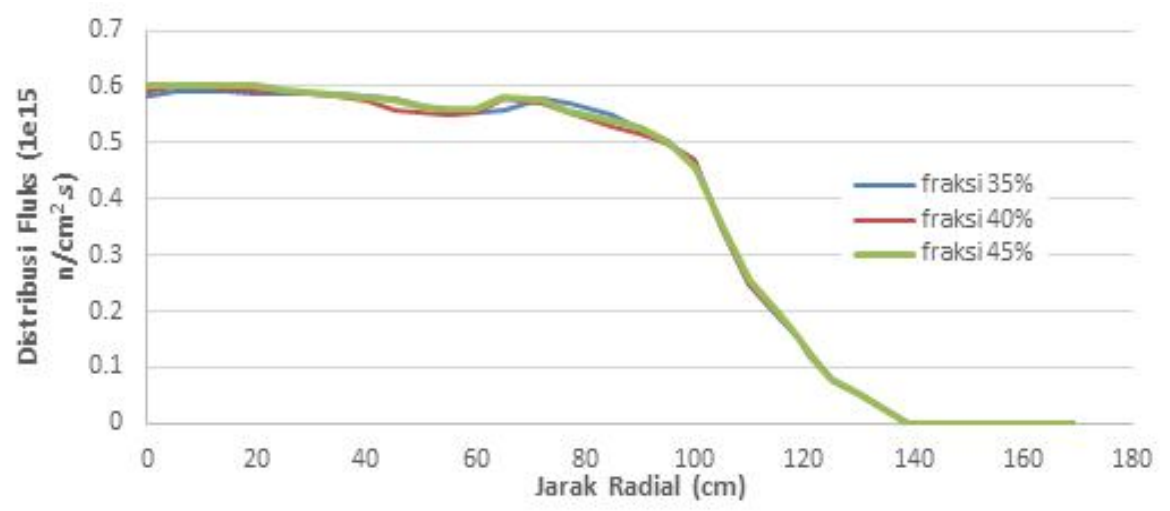

Gambar 1 Distribusi fluks neutron arah radial dalam 1 siklus operasi

Nilai distribusi fluks neutron arah aksial yang diperoleh memiliki pola yang sama dengan dengan distribusi fluks neutron arah radial. Hal ini dikarenakan nilai fraksi enrichment yang digunakan sama. Distribusi fluks neutron untuk arah aksial dapat dilihat pada Gambar 2.

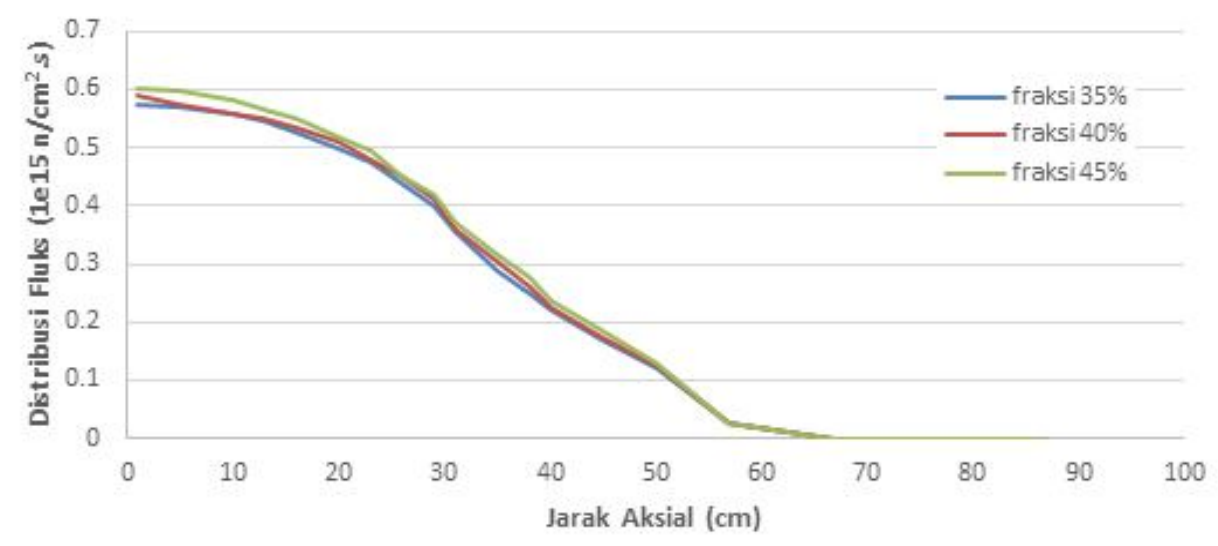

Gambar 2 Distribusi fluks neutron dalam arah aksial

\subsection{Distribusi Daya}

Nilai distribusi daya paling tinggi dihasilkan pada bagian tengah teras dan menurun pada bagian luar dan mencapai nol pada bagian reflektor. Hal ini karena pada bagian tengah teras berisi bahan bakar fisil dan pada reflektor hanya berisi bahan yang berfungsi untuk merefleksikan atau menghambukan bocoran neutron sehingga masuk lagi ke teras.

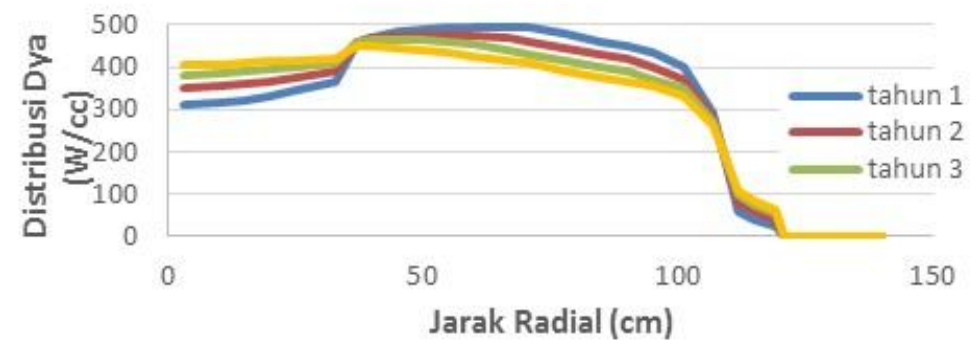

Gambar 3 Distribusi daya arah radial

Nilai distribusi daya paling tinggi dihasilkan pada bagian tengah teras dan menurun pada bagian luar dan mencapai nol pada bagian reflektor. Hal ini karena pada bagian tengah 
teras berisi bahan bakar fisil dan pada reflektor hanya berisi bahan yang berfungsi untuk merefleksikan atau menghambukan bocoran neutron sehingga masuk lagi ke teras.

Tabel 2 Nilai power peaking reaktor (ppf)

\begin{tabular}{cccc}
\hline \multirow{2}{*}{ Tahun } & \multicolumn{3}{c}{ Power Peaking Reactor } \\
\cline { 2 - 4 } & Fraksi 35\% & Fraksi 40\% & Fraksi 45\% \\
\hline 1 & 2,3779 & 2,2153 & 2,2099 \\
2 & 2,0101 & 2,0769 & 2,0803 \\
3 & 1,9182 & 1,9359 & 1,9660 \\
4 & 1,7699 & 1,8047 & 1,8321 \\
\hline
\end{tabular}

Nilai ppf yang diperoleh dapat dinyatakan bahwa fraksi bahan bakar $45 \%$ memiliki nilai ppf yang lebih stabil. Hal ini berarti reaktor dapat beroperasi tanpa melakukan refueling lebih lama dibandingkan dengan fraksi bahan bakar 35\% dan 45\%. Distribusi daya pada arah aksial dapat dilihat pada Gambar 4.

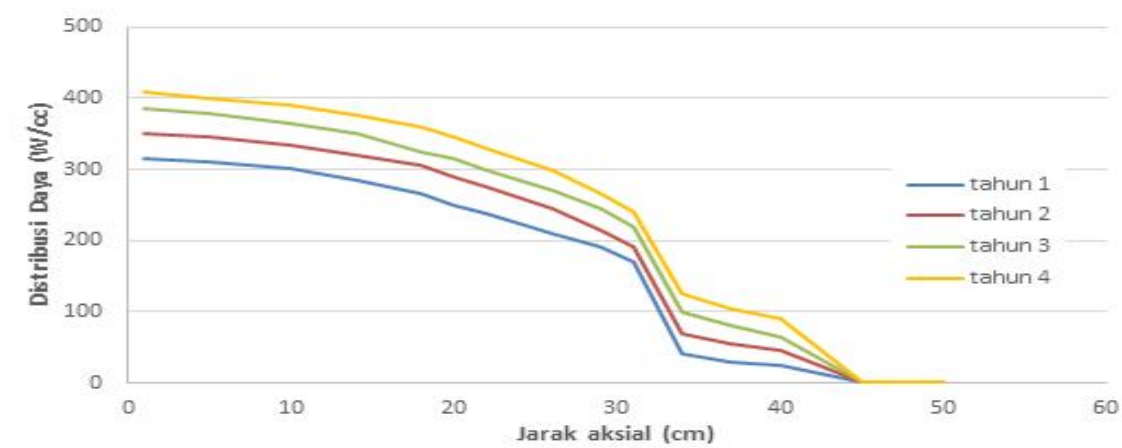

Gambar 4 Distribusi daya arah aksial

Karakteristik distribusi daya pada arah aksial memiliki pola yang sama dengan distribusi daya pada arah radial. Hal ini dikarenakan konfigurasi teras yang digunakan pada arah radial dan aksial serta pola pengisian yang sama.

\subsection{Perubahan Densitas Bahan Bakar}

Densitas ${ }^{238} \mathrm{U}$ terus mengalami penurunan setiap tahunnya, hal ini karena ${ }^{238} \mathrm{U}$ mengalami dua reaksi selama proses pembakaran yaitu reaksi tangkapan neutron (capture) dan peluruhan. Pada reaksi capture ${ }^{238} \mathrm{U}$ akan menghasilkan bahan bakar baru berupa ${ }^{239} \mathrm{Pu}$ yang merupakan bahan bakar fisil. Selama reaktor beroperasi diharapkan densitas ${ }^{238} \mathrm{U}$ bernilai stabil, sehingga bahan bakar dalam reaktor dapat digunakan dalam jngka waktu yang lama.

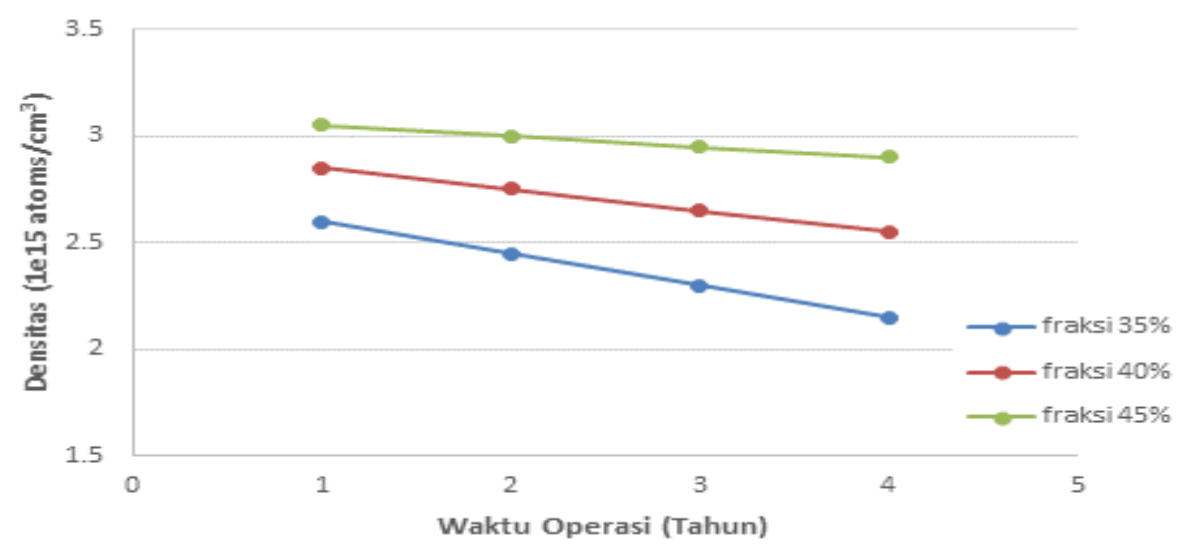

Gambar 5 Preubahan densitas ${ }^{238} \mathrm{U}$ dalam 1 siklus (4 tahun) operasi 
Niai densitas uranium sebagai bahan bakar fertil terus mengalami penurunan, hal ini dikarenakan uranium mengalami reaksi fisi dan tangkapan neutron. Reaksi fisi pada uranium akan menghasilkan dua atom baru, sedangkan pada tangkapan neutron akan menghasilkan atom ${ }^{239} \mathrm{Pu}$. Seiring berkurangnya nilai densitas uranium nilai densitas ${ }^{239} \mathrm{Pu}$ sebagai bahan bakar fertil yang diperoleh mengalami peningkatan. Nilai densitas ${ }^{239} \mathrm{Pu}$ dapat dilihat pada Gambar 6 .

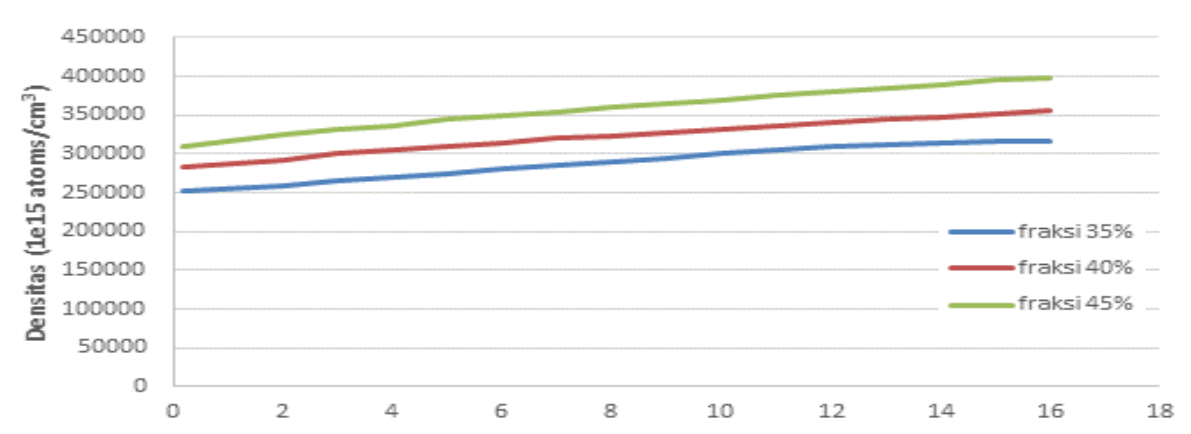

Gambar 6 Densitas ${ }^{239} \mathrm{Pu}$ dalam 1 siklus (4 tahun) operasi

Nilai densitas ${ }^{239} \mathrm{Pu}$ berbanding lurus dengan nilai fraksi bahan bakar yang digunakan. Hal ini disebabkan karena reaksi fisi dan tangkapan neutron lebih banyak terjadi pada fraksi bahan bakar yang lebih tinggi. Nilai densits juga dipengaruhi oleh penampang lintang makroskopik, kontanta peluruhan radio aktif dan fluks neutron dalam teras reaktor.

\subsection{Nilai Breeding Ratio}

Nilai breeding ratio untuk masing-masing fraksi bahan bakar mengalami penurunan setiap tahunnya. Artinya semakin lama reaktor beroperasi maka bahan bakar fisil yang diproduksi semakin berkurang. Nilai breeding ratio tertinggi diperoleh pada fraksi bahan bakar $35 \%$, akan tetapi pada fraksi ini mengalami penurunan yang siknifikan. Penurunan nilai breeding ratio yang signifikan akan mengakibatkan bahan bakar yang diproduksi akan semakin sedikit, dan mengakibatkan bahan bakar dalam teras akan cepat habis. Dari data ini dapat disimpulkan bahwa nilai breeding ratio paling efektif berada pada fraksi bahan bakar $45 \%$. Hal ini karena pada fraksi $45 \%$ diperoleh nilai yang lebih konstan. Niali breeding ratio yang diperoleh dapat dilihat pada Gambar 7.

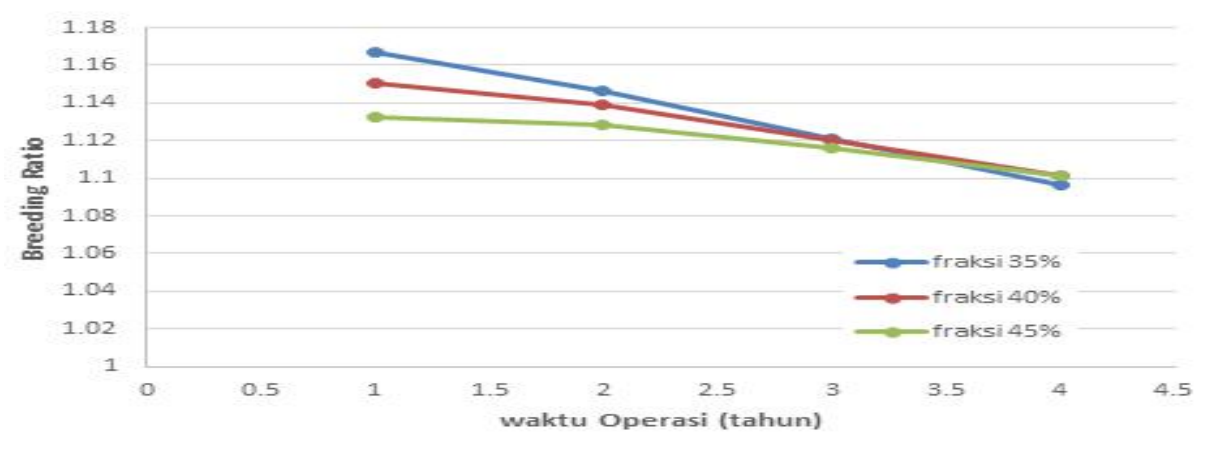

Gambar 7 Nilai breeding ratio dalam 1 siklus operasi

\subsection{Nilai Burn Up}

Nilai burn up yang diperoleh berbanding terbalik dengan fraksi bahan bakar yang digunakan. Hal ini disebabkan karena semakin keci fraksi bahan bakar yang digunakan akan mengakibatkan jumlah bahan bakar yang digunakan semakin banyak untuk proses pembakaran atau reaksi fisi. Nilai burn up paling kecil diperoleh pada fraksi bahan bakar 45\%, sehingga dapat dinyatakan bahwa fraksi bahan bakar $45 \%$ lebih tahan lama dibanding dengan fraksi 
bahan bakar 35\% dan $45 \%$. Nilai burn up yang diperoleh selama reaktor beroperasi dapat dilihat pada Gambar 8.

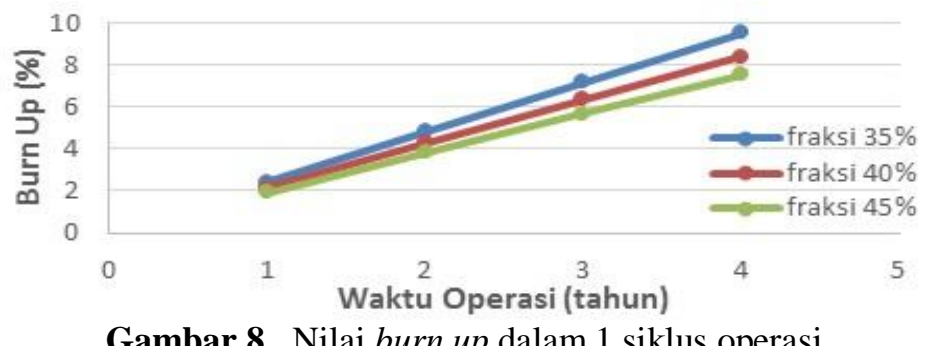

Gambar 8 Nilai burn up dalam 1 siklus operasi

\section{KESIMPULAN}

Berdasarkan penelitian yang telah dilakukan dapat diambil kesimpulan bahwa hasil penelitian menunjukkan bahwa kekritisan reaktor dapat dipertahankan dengan cara pengaturan enrichment bahan bakar. Semua fraksi bahan bakar yang disimulasikan menghasilkan nilai breeding ratio besar dari 1. Reaktor dengan fraksi bahan bakar 35\% menghasilkan breeding ratio yang besar, tetapi pada fraksi bahan bakar $45 \%$ menunjukkan nilai yang lebih seimbang dalam hal pembiakan. Nilai burn up paling efektif diperoleh pada simulasi dengan fraksi bahan bakar $45 \%$, dimana nilai burn up terkecil yaitu 1,9\% dan nilai terbesar adalah 7,5\% dan juga pada fraksi $45 \%$ memiliki nilai yang lebih stabil dibanding dengan fraksi bahan bakar lainnya.

\section{DAFTAR PUSTAKA}

Arisa, D, "Analisis Pembiakan (Breeding) Plutonium-239 pada Reaktor Pembiak Cepat Berpendingin Logam Cair (LMFBR) dengan Variasi Geometri Teras dan Ukuran Teras Reaktor" Skripsi S1, Universitas Andalas, Padang, 2008.

Cinantya, N. D. dan Fitriyani, D., Analisis Neutronik Pada Reaktor Cepat Dengan Variasi Bahan Bakar (UN-PuN, UC-PuC dan MOX), Jurnal Fisika Unand, 1 - 7, 2014.

Fitriyani, D, "Studi Desain Reaktor Daya Nuklir Berbasis Kapal", Disertasi S2, Institut Teknologi Bandung, Bandung, 2006.

Nurwinda, "Analisis Difusi Neutronik pada Reaktor Cepat dengan Variasi Bahan Pendingin (Na, NaK, Pb-Bi)", Skripsi S1, Universitas Andalas, Padang, 2009.

Smith, G. D, "Numerical Solution of Partial Difential Equation :Finite Difference Methods, (Oxford Applied Mathematics and Computating Science Series, third Edition, Oxford, 1985), hal. $262-272$. 